\title{
Protection of the health and safety of port workers exposed to air chemical agents at work
}

\author{
E. Vafaki ${ }^{1} \&$ G. Palantzas ${ }^{2}$ \\ ${ }^{1}$ Thessaloniki Port Authority S.A., Greece \\ ${ }^{2}$ Aristotle University of Thessaloniki, Greece
}

\begin{abstract}
According to the International Labour Organization (ILO), the principal health hazards that can arise from port operations are, among others, fumes, dust and exposure to hazardous air chemical substances. Such health hazards should be identified, the risks known and evaluated, the dangers to health understood and effective preventative measures put in place to ensure the health of the port workers concerned. Although this acknowledgement, over the last years many accidents keep occurring in port staff resulting from exposure to air pollutants. Particulate matters, benzol, volatile organic compounds, nitrogen oxides, sulphur oxides, carbon monoxide, formaldehyde, heavy metals, dioxins, pesticides used to fumigate produce are almost common air pollutants meet in port facilities. The set up of a monitoring system on air pollutants concentrations and health effects in port areas has been mentioned by ILO as the crucial step towards the integrated management of these issues. The application of such a system by the port of Thessaloniki since 2003 and the production of representative long data and time series addressing air chemical agents presented in the port, indicate the complexity of the problem and the need of an integrated approach towards managing air pollutants. In this paper, the importance of an integrated protection from exposure to air pollutants at port work is mentioned, the main air chemical agents are presented in terms of their risk, a brief reference on legislative and regulatory framework on the issue is done and the main measures and actions for tackling the problem are outlined. Additional relevant data, measurements and practices coming from the port of Thessaloniki act as a case study, as the main aim of the paper is to be concerned by other port authorities, in terms of information, good practices and experience exchange.
\end{abstract}

Keywords: port, workers, health and safety, air quality, chemical agents. 


\section{Introduction}

Health and safety at work is an area where there have been considerable developments during the last two decades, particularly in the European Union where there is a range of directives relating to it [1]. Ports are also influenced by developments in the field of health and safety in general.

Health and safety, as an issue that defines ways of both working and behaving, is kept today high in the agenda of the most ports corporate policy, and specific organizational structures have been put in place to ensure a safe and healthy workplace in both day-to-day operation and long-term development.

However, in general, few ports throughout Europe and World have declared a Health and Safety Policy Statement or/and develop and implement some form of Health and Safety Management System. Financial constraints, lack of cooperation among employer, employees and their unions, insufficient information provided to employees on Health and Safety diseases, inadequate performance of duties by the safety technician, ambiguity of the roles of various ministries and lack of collaboration, inadequate national legislative framework, lack of conformance controls by competent authorities, workers' unwillingness to adapt to provisions and rules, are the main reasons contributed to this fact [2].

In this framework, one of the most crucial parts of the health and safety management in ports concerns the air chemical agents [3], which means any chemical element or compound, on its own or admixed, as it occurs in the natural state or as produced, used or released, including release as waste, by any work activity, whether or not produced intentionally and whether or not placed on the market [4].

The port is an area characterized by a wide range and variety of workplaces and workstations, electronic and mechanical equipment and machines, working methods and cargo-type distribution. As a result, a variety of risk arising from chemical agents can affect the health and safety of workers. Chemical agents can be present during the work of cargo loading/uploading of ships and in many work operations.

The presence of chemical agents varies by port to port, since each port is unique in terms of commercial profile, cargo handling processes and working culture.

Activities that are currently widely used in ports for improving health and safety relate to the organisation of safety, improvement of the working environment, monitoring, hazard identification and emergency preparation $[5,6]$.

The port of Thessaloniki in Greece, in compliance with its environmental commitment applies since 2007 a monitoring program for chemical agents at work. The aim is to evaluate all workplaces in terms of chemical agents' levels and identify the necessary techniques and administrative procedures required for eliminating and managing any irregularities towards the health and safety of the personnel. 


\section{Management of air chemical agents in ports}

\subsection{Presence of chemical agents and regulatory framework}

Diesel engines at ports create vast amounts of air pollution affecting the health of port workers, while other major air pollutants from diesel engines that affect human health include particulate matter, volatile organic compounds (VOCs), nitrogen oxides (NOx), ozone (O3), and sulfur oxides (SOx). The health effects of such chemical agents may include asthma, other respiratory diseases, cardiovascular disease, lung cancer, and premature death $[7,8]$.

Chemical agents can be emitted by terminal machinery, trade cars, passenger vehicles, Ro-Ro vehicles, trade wheeled cargo vehicle exhausts and cargo fumes, and can present harmful health risks from: carbon monoxide and dioxide, polycyclic aromatic hydrocarbons, oxides of nitrogen, sulphur oxides, aldehydes, particulate matter, carcinogens and mutagens [9].

The international concern for Health and safety issues in port workplaces has been regulated in 1929 through the International Labour Organization (ILO) Convention on the protection against accidents of workers employed in loading or unloading ships [10], which has been revised in 1932 and 1979 [11, 12]. ILO so far has published relevant codes and manuals, such as the "Code of Practice on Safety and Health in Ports", the "Port Safety and Health Audit Manual" and the "Guidelines on occupational safety and health management systems" [13]. These publications provide a unique and powerful instrument for the development of a sustainable safety culture within ports and beyond.

The European Union (EU) action in health and safety at work has its legal basis in Article 137 of the EU Treaty, while the improvement of health and safety of the workers already started from 1952 under the European Coal and Steel Community. Since then a solid corpus of relevant legislation has been adopted [14], while the following Directives have been mainly contacted specifically for chemical agents: Council Directive 98/24/EC on the protection of the health and safety of workers from the risks related to chemical agents at work, Council Directive 83/477/EEC and its amendments on the protection of workers from the risks related to exposure to asbestos at work, Commission Directive 2006/15/EC establishing a second list of indicative occupational exposure limit values, Directive 2004/37/EC on the protection of workers from the risks related to exposure to carcinogens or mutagens at work, Commission Directive 91/322/EEC on establishing indicative limit values on the protection of workers from the risks related to exposure to chemical, physical and biological agents at work and Commission Directive 2000/39/EC establishing a first list of indicative occupational exposure limit values on the protection of the health and safety of workers from the risks related to chemical agents at work.

As national laws and local requirements on Health and Safety issues vary among countries and each port is unique in terms of commercial profile, cargo handling processes and working culture, each port needs to develop working practices that will safeguard the safety and health of port workers from air chemical agents in the light of its own specific circumstances. 


\subsection{Measurement of chemical agents}

Measurement of air chemical agents concentrations in ports are required for a number of reasons, including to:

- Help assess possible health risks resulting from port work activities,

- Determine compliance with occupational exposure limits (OELs),

- Determine the need for, and the effectiveness of, exposure controls,

- Determine which work tasks give rise to the most exposure,

- Investigate complaints concerning alleged health effects,

- Reassure port workers, who may be exposed to chemical agents,

- Comply with specific legal requirements.

The chemical agents' Occupational Exposure Limits (OELs) are concentrations under which workers may be repeatedly exposed, day after day, without adverse health effects. OELs generally refer to 8-hour time-weighted average (TWA) concentrations. Some chemical agents also have short term exposure limits (STELs) which represent the allowable concentration over 10-15 minute periods. Excursions above the 8-hour TWA, OEL are permissible as long as the TWA concentration over the work shift is within the limit. For substances without STELs, it has been suggested that such excursions should not normally exceed 2-5 times the 8-hour TWA OEL, averaged over a 10-15 minute period [15]. It should be noted that in some countries there are specific regulatory requirements covering compliance with OELs which need to be taken into account when designing a measurement programme.

As the results of measurements may form the basis of significant decisions on possible health risks on port workers, it is important that compliance with regulations and investment in control measure is undertaken in a structured and meaningful way. The following aspects should be considered:

(a) The chemical agents that should be measured should comply with the specific workplace and the relevant exposure to ambient sources. In addition, if chemical products are used, the applicable OELs should be provided on the supplier's safety data sheet. If not, the supplier should be contacted for further information.

(b) To demonstrate that exposure does not exceed the OEL, the sample collected should be representative of the air which port worker breathe. For example, a measurement taken very close to a source of chemical agent is only representative of exposure if the worker actually works in that location.

(c) Generally, chemical agents levels associated with a particular port work activity vary considerably both by location and time. Measurement programmes need to take account of this variation.

(d) There are 3 basic types of measurement: i. Short term or 'spot' measurements. These are measurements taken over a short time period (e.g. a few minutes) at a single point in the workplace. They give a rough indication of the concentration at a particular time and location. ii. Measurement of average concentration over a given time period. These measurements, represented by the TWA are particularly useful for measuring personal exposure by sampling air from the breathing zone of a port worker. The results can be compared directly with OELs. iii. Continuous measurement of concentration at a single location. 
These provide a continuous measure of the concentration at a particular time and location in the workplace.

(e) Measurements for comparison with OELs should be made during the whole period of 'typical' port work activities during which exposure would be expected to occur. The measurements need to confirm that TWA exposure for the whole work shift is below the OEL, exposures during short term tasks are within any short term exposure limits/excursion rules. Measurements taken for other reasons, for example to identify chemical agents' emission sources or for confined space entry, are generally taken over much shorter periods using different techniques.

\subsection{Interpretation of the results of the measurements}

The frequency of periodic measurements in the port workplaces depends upon the level of exposure. Typically, low sampling frequencies (for example, once a year) can be applied where exposures are well below OELs, and where workplace conditions are stable and predictable. On the other hand, more frequent sampling (for example, once a month or more) may be desirable where exposures are nearer OEL levels, and where workplace conditions, which give rise to exposures, are unstable and unpredictable.

All port work activities should be subject to periodic risk assessment which aims to identify hazards from chemical agents and confirm that appropriate control measures are in place to ensure that the activity is safe [16, 17]. Where chemical agents or/and chemical products are presented/involved, measurement of chemical agents' levels should be a necessary part of the risk assessment. Numerical results should be supported by, and interpreted in light of, other information, such as the presence/performance of ventilation systems, observations of work procedures, views/experience of those conducting the work, good custom and practice within the industry.

Consideration of the results of exposure measurements should lead to answers to the following questions: a) is immediate action necessary to eliminate or reduce exposure?, b) is a programme of planned improvements necessary?, c) are more detailed measurements required?

Most national health and safety regulations include requirements to keep exposure to chemical agents within OELs. In some cases, there is also a requirement to reduce exposure 'as far as is reasonably practicable', that is to say, where the cost of additional controls is reasonable in relation to the reduction in risk they can achieve [18].

\subsection{Control options}

A range of possible general approaches (technical, organizational, medical) are available to minimise chemical agents' exposure in a port workplace:

- Process design: to minimise chemical agent release, spills and loss from chemical products,

- Workplace arrangement: to segregate areas with higher chemical agents' levels and minimise the number of people exposed, 
- Local exhaust ventilation: to remove chemical agents close to its point of release,

- General or dilution ventilation: to adequately dilute released vapours from chemical agents and directed so as to carry vapour away from working areas,

- Procedures: to minimise chemical agents' production and release.

The following actions should be a part of an integral or independent programme for the management of chemical agents, which may be further support the health and safety risk assessment process in a port.

- Identification of the regulatory framework and legal obligations.

- Categorization of port workplaces personnel.

- Identification of hazards and risk assessment by each workplace through on-site study and monitoring.

- Assessment of the risks.

- Providing of adequate information, training, instructions and personal protective equipment to port personnel and workers.

- Arrangements to deal with accidents, incidents and emergencies.

- Health surveillance.

- Implementation of control measures and practices to avoid and reduce the risks.

- Continuous monitoring, auditing and reviewing of the work environment, work practices and equipment, in consultation, where appropriate, with all employees.

The effective control of chemical agents may have cost-saving benefits such as reducing loss working days and medical attendance cost. Exposure to chemical agents can be reduced by the use of appropriate protective equipment, providing of adequate information and training, prohibition of entrance into specific workplaces, progressive replacement of old type equipment, appropriate maintenance of the work equipment and workplaces systems, instructions to use work equipment correctly, limitation of the duration and intensity of the exposure, appropriate work schedules with adequate rest periods, health surveillance.

\section{Case study: monitoring of air chemical agents in the Port of Thessaloniki}

\subsection{The port's activity}

The Port of Thessaloniki in Greece is a typical commercial port that serves activities and operations associated mainly with container handling, general, dry and bulk cargo handling, and services to coastal shipping and to cruise ships. In these terms, the port is characterized by a variety of work practices, equipment and working places that could affect negatively not only the environment but the employees' welfare and people living in nearby communities. The port is today the most proactive, among the Greek ports, in the field of environmental and occupational health and safety management. In 2003 the port was certified according to the "PERS" (Port Environmental Review System) standard [19]. A basic element of port's environmental policy is referred to health and safety and as it is declared in its Environmental Policy "Thessaloniki Port Authority is 
committed to high standards of occupational safety and health in order to safeguard the well being of those working at, visiting or living near our operation" [20].

Thessaloniki Port Authority (THPA), in compliance with its commitment and as an answer to the driving forces for an integrated management of Health and Safety issues in ports, in 2007 went ahead for implementation of the OHSAS 18001 standard. THPA aims to achieve the certification for the entire company in 2011. This evolution has its basis in 2006, when the Health and Safety Office of the THPA decided to improve progressively year-by-year the health and safety issues awareness and importance at all port personnel and port users. THEPA recorded no accidents/incidents occurred in 2008 and 2009 coming from air pollutants.

\subsection{The application of the monitoring program}

Under this framework, from 2007 the Port of Thessaloniki is conducting an air quality monitoring program focusing on health and Safety at work within its operational region of influence. This monitoring program supports the Port's commitment to improve health and safety and also air quality within the port, by helping to better manage and provide feedback on the Port's air quality improvement efforts. The monitoring program includes a network of 8 workplaces where a comprehensive set of air chemical agents at work are measured.

The monitoring workplaces are strategically selected at (1) Workshop (maintenance and repair of work machinery), (2) Gatehouses, (3) Warehouses, (4) Ship hold, (5) On forklift, (6) Container terminal, (7) On bulk cargoes dock, (8) Silo. Selection of the locations was dependent on a special "validation study" to ensure that the monitoring sites were representative of working conditions within the port.

The program includes a number of 9 chemical agents: Nitrogen dioxide (NO2), Carbon monoxide (CO), Carbon dioxide (CO2), Total solid particulates (TSP), Petroleum Hydrocarbons (TPH), Benzene (C6H6), Ethanol (C2H6O), Chloroform (CHCl3), Phosphine (PH3), Total solid particulates (TSP).

As part of the program, a meteorological monitoring station operates to help interpret the air quality data and for use in other port programs. The meteorological monitoring station collects wind speed, wind direction, and temperature data.

A wide range of techniques and equipment are available for measuring air chemical agents' concentrations. They can all help in the process of assessing and controlling exposures to chemical agents in the workplace, but it is essential that the appropriate equipment is selected, that it is used properly and that the results are interpreted correctly.

The measurements are made on short term or 'spot' level, taken over a short time period ( 3 minutes) at a single point in the workplace, given generally a good indication of the concentration at the particular time and location. Thus, comparing these data with the limit values proposed by the legislation, appropriate organizational and technical measures can be done towards health 
and safety improvement. All measurements are made with the DRAGER CMS control set, except the ones for phosphine which are made with the DRAGER Regard-1 control set. For its workplace and chemical agent there are weekly measurements, thus 52 values per year.

\subsection{Measurements and results}

Tables 1 and 2 provide summaries of the particulate data measured at the eight workplaces for nine chemical agents within the Port of Thessaloniki. The tables depict annual averages. More detailed tables showing weekly and monthly variations are archived. These averages reduce the day-to-day variability in the data, making it easier to determine the longer-term data trends. The level of measurements varies due to a number of reasons, including the time of year, the cargo engaged and changes in the weather and work pressure.

Figure 1 depicts the distribution of the max, min and mean values of the concentrations of the chemical agents measured between the years 2007-2009 in all workplaces of the port.

Chemical agents' levels do not, in general, exceed the limit values, as the design and layout of the workplaces (open areas, limited number of personnel per workplace), the appropriate maintenance of the work equipment and

Table 1: Mean annual concentrations (in ppm) of chemical agents at work for 2009, in different port workplaces.

\begin{tabular}{|c|c|c|c|c|c|}
\hline & Workshop & Gatehouses & Warehouses & Ship hold & Limit value \\
\hline $\mathbf{N O}_{\mathbf{2}}$ & 0.5 & 1.2 & 1 & - & $5 \mathrm{ppm}$ \\
\hline $\mathbf{C}_{\mathbf{6}} \mathbf{H}_{\mathbf{6}}$ & - & 0.5 & 0,2 & - & $1 \mathrm{ppm}$ \\
\hline $\mathbf{T P H}$ & 10 & 58 & 2 & 90 & $500 \mathrm{ppm}$ \\
\hline $\mathbf{C O}$ & 3 & 5 & - & - & $10 \mathrm{ppm}$ \\
\hline $\mathbf{C O}_{2}$ & 1260 & 1050 & - & - & $5000 \mathrm{ppm}$ \\
\hline $\mathbf{C}_{\mathbf{2}} \mathbf{H}_{\mathbf{6}} \mathbf{O}$ & - & - & - & - & $1000 \mathrm{ppm}$ \\
\hline $\mathbf{C H C l}_{\mathbf{3}}$ & - & - & 0.3 & - & $50 \mathrm{ppm}$ \\
\hline $\mathbf{P H} \mathbf{H}_{3}$ & - & - & 0.09 & - & $0,3 \mathrm{ppm}$ \\
\hline $\mathbf{T S P}$ & 13 & - & 19 & - & $10 \mathrm{mg} / \mathrm{m}^{3}$ \\
\hline
\end{tabular}

Table 2: $\quad$ Mean annual concentrations (in ppm) of chemical agents at work for 2009, in different port workplaces.

\begin{tabular}{|c|c|c|c|c|c|}
\hline & On forklift & $\begin{array}{c}\text { Container } \\
\text { terminal }\end{array}$ & $\begin{array}{c}\text { Bulk cargoes } \\
\text { terminal }\end{array}$ & Silo & Limit value \\
\hline $\mathbf{N O}_{\mathbf{2}}$ & - & - & - & - & $5 \mathrm{ppm}$ \\
\hline $\mathbf{C}_{\mathbf{6}} \mathbf{H}_{\mathbf{6}}$ & 0,3 & 0,5 & 0,3 & - & $1 \mathrm{ppm}$ \\
\hline $\mathbf{T P H}$ & 10 & - & - & - & $500 \mathrm{ppm}$ \\
\hline $\mathbf{C O}$ & 2 & 3 & 1 & - & $10 \mathrm{ppm}$ \\
\hline $\mathbf{C O}_{2}$ & 1006 & 1090 & 956 & - & $5000 \mathrm{ppm}$ \\
\hline $\mathbf{C}_{\mathbf{2}} \mathbf{H}_{\mathbf{6}} \mathbf{O}$ & - & - & 1.9 & - & $1000 \mathrm{ppm}$ \\
\hline $\mathbf{C H C l}_{\mathbf{3}}$ & - & - & 1.7 & - & $50 \mathrm{ppm}$ \\
\hline $\mathbf{P H}_{3}$ & 0.11 & - & 0.12 & 0.17 & $0,3 \mathrm{ppm}$ \\
\hline $\mathbf{T S P}$ & 16 & - & 27 & 34 & $10 \mathrm{mg} / \mathrm{m}^{3}$ \\
\hline
\end{tabular}


workplaces, and the correct use of the work equipment reduce the presence of high concentration levels. Phosphine represented an aspect for which an individual action plan was carried out.

Based on the risk assessment, a series of technical, organizational and medical prevention measures were taken: availability of individual protective equipment to workers (e.g. air respirators, air-purifying respirators), providing of adequate information and training, prohibition of entrance into specific workplaces, progressive replacement of old type equipment (e.g. forklifts), appropriate maintenance of the work equipment and workplaces systems (e.g. snails, vehicles), instructions to use work equipment correctly, limitation of the duration and intensity of the exposure, appropriate work schedules with adequate rest periods, health surveillance.

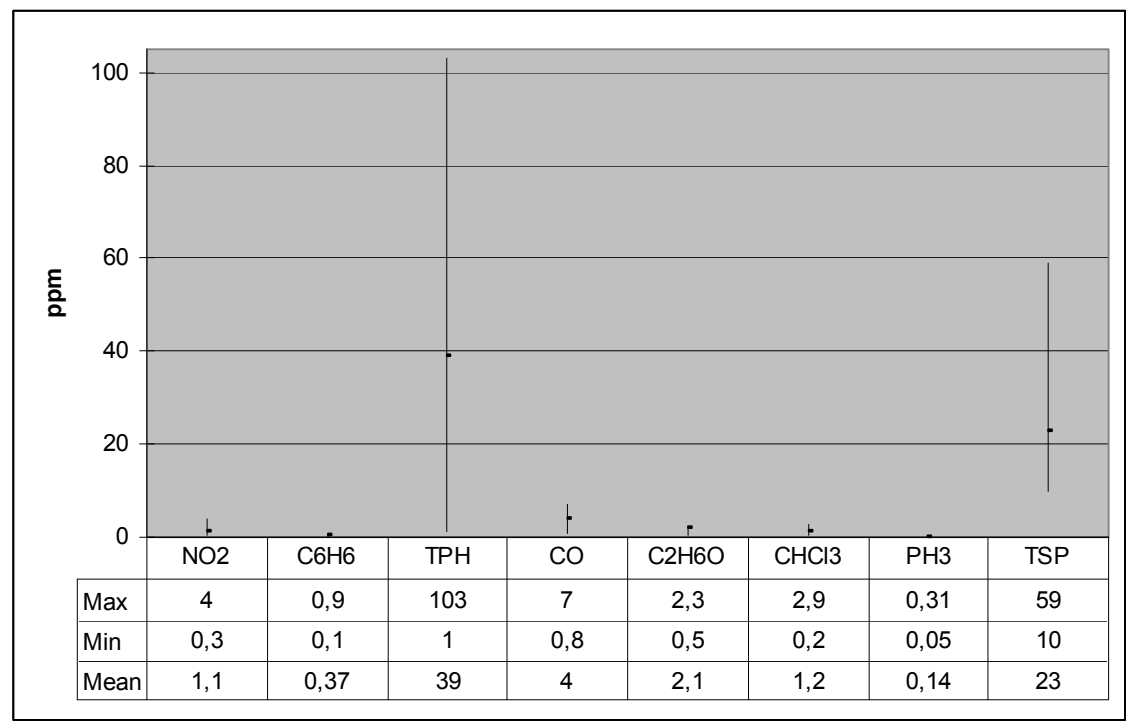

Figure 1: Distribution of the chemical agents' concentration within all workplaces of the port for the period 2007-2009.

\section{Conclusion}

Health and safety at a port-working environment is an important part of any structured and sensitive port authority. This paper aims to underline the possibilities presented to commercial ports to evaluate and manage in a practicable and effective manner the health and safety issues related to air chemical agents, in their working environment, as chemical agents can threaten seriously the health of port personnel.

Worldwide, chemical agents are consistently identified as a high-priority problem in many ports. The presence of chemical agents in a port depends on 
various parameters, like the type of cargo handled and distributed, the point of the release, the wind and the location of risk groups and workplaces.

The categorization of the workplaces and the determination of the chemical agents sources, in combination with systematic measurements, consist an integral part of an adequate occupational risk assessment. The measurements evaluation, the personnel information and training, the health surveillance and the preventive and control measures, complete the necessary framework in which a progressive integrated management of chemical agents risk in ports can be designed.

The work presented can be concerned by other port authorities, in terms of information exchange and experience diffusion.

\section{References}

[1] Beresford A.K.C. et al., (2004). The UNCTAD and WORKPORT models of port development: evolution or revolution? Maritime Policy and Management, 31 (2), pp. 93-107, 2004.

[2] Vafaki E. \& Palantzas G., Practices and methodologies for an integrated management of health and safety issues in ports. Proc. of the 4th Int. Conf. On Prevention of Occupational Accident in a Changing Work Environment, 2008.

[3] Koutitas C., Vafaki E. \& Palantzas G., Facing the problem of the fugitive dust in commercial city-ports. The port of Thessaloniki case study. Proc. of the $1^{\text {st }}$ Int. Conf. on Harbours \& Air Quality, eds. E. Canepa \& E. Georgieva, SGEditoriali: Padova, pp. 291-300, 2005.

[4] Council Directive 98/24/EC on the protection of the health and safety of workers from the risks related to chemical agents at work. eurlex.europa.eu/en/index.htm

[5] EU 89/655/EEC Council Directive concerning the minimum safety health requirements for the use of work equipment by workers at work. eurlex.europa.eu/en/index.htm

[6] Council Directive $89 / 656 /$ EEC on the minimum health and safety requirements for the use by workers of personal protective equipment at the workplace. eur-lex.europa.eu/en/index.htm

[7] Occupational Safety and Health Service, Department of Labour, Code of practice of health and safety in port operations, OSHS: New Zealand, 2004.

[8] Natural Resources Defence Council, Harboring Pollution - Strategies to Clean Up U.S. Ports, NRDC: New York, 2004.

[9] International Labour Organization, Code of practice on safety and health in ports, ILO Publications: Geneva, 2005

[10] International Labour Organization, Convention C028, Protection against Accidents of Workers Employed in Loading or Unloading Ships. www.ilo.org/ilolex/cgi-lex/convde.pl?C028

[11] International Labour Organization, Convention C152, Occupational Safety and Health in Dock Work. www.ilo.org/ilolex/cgi-lex/convde.pl?C152 
[12] International Labour Organization, Recommendation No 160 concerning Occupational Safety and Health in Dock Work. www.ilo.org/ilolex/cgilex/convde.pl?R160

[13] International Labour Organization, Guidelines on occupational safety and health management systems, ILO Publications: Geneva, 2001.

[14] European Commission, Employment, Social Affairs and Equal Opportunities, Health and Safety at Work.ec.europa.eu /social $/$ main.jsp?catId $=148 \&$ langId $=$ en

[15] European Agency for Safety and Health at Work, Occupational Exposure Limits, What are Occupational Exposure Limits? http://osha.europa.eu /en/topics/ds/oel

[16] G. Fava \& M. Letizia Ruello, Air pollution from traffic, ships and industry in an Italian port. Proc. of the $16^{\text {th }}$ Int. Conf. on Modelling, Monitoring and Management of Air Pollution, eds. C.A. Brebbia, J.W.S. Longhurst, WIT PRESS: Southampton and Boston, pp. 271-280, 2008

[17] Moreno N., Alastuey A., Ouerol X., Artiñano B., Guerra A., Luaces J.A., Lorente A., Basora J., Characterisation of dust material emitted during harbour operations (HADA Project), Atmospheric Environment, 41(30), pp. 6331-6343, 2007.

[18] Georgieva E., Canepa E., Builtjes P., Harbours and air quality, Atmospheric Environment, 41(30), pp. 6319-6321, 2007.

[19] ECOPORTS, Tool 4: Port Environmental Review System (PERS), www.ecoports.com/page.ocl?pageid $=30$

[20] Thessaloniki Port Authority, Environmental Policy Statement, www.thpa.gr 